\title{
Toward a Militant Pedagogy in the Name of Love: On Psychiatrization of Indifference, Neurobehaviorism and the Diagnosis of ADHD-A Philosophical Intervention
}

\author{
Mattias Nilsson Sjöberg1 ${ }^{1}$
}

Published online: 27 January 2018

(C) The Author(s) 2018. This article is an open access publication

\begin{abstract}
Neuro)psychiatric diagnoses such as attention deficit hyperactivity disorder (ADHD) is a rapidly growing and globally increasing phenomenon, not least in different educational contexts such as in family and in school. Children and youths labelled as ADHD are challenging normative claims in terms of nurturing and education, whereas those labelled as ADHD are considered a (future) risk for society to handle. The dominant paradigm regarding ADHD is biomedical, where different levels of attention and activityimpulsivity are perceived as neurobiological dys/functions within the brain best managed by means of an individual diagnosis and instrumental pedagogy. The majority of those labelled as having ADHD encounter a dominant educational model in the form of what is referred to in this article as neurobehaviorism, which is based on onto-epistemological violence. As opposed to this act of violence against being - and against the psychiatrized subject - a less violent educational model is proposed, based on French philosopher Alain Badiou's ontological examination of being and his concept of love as a truth procedure. In terms of the latter, the focus is on the potential of the encounter as a 'Two scene of love'. Here, the encounter is a place where it is possible to create new truths and subjects, instead of taking the individual diagnosis as an axiom which only leads to individuals having fixed identities codified in a hierarchical order. This argument is drawn from the 'mathematical' formula $1+1=\underline{\boldsymbol{\varepsilon}}$, which originates from an online forum for people who have come into contact with ADHD in one way or another.
\end{abstract}

Keywords ADHD $\cdot$ Alain Badiou $\cdot$ Behaviorism $\cdot$ Education $\cdot$ Philosophy · Psychiatrization

Mattias Nilsson Sjöberg

mattias.nilsson_sjoberg@soc.lu.se

1 Lund University, Paradisgatan 5, 22100 Lund, Sweden 


\section{Introduction: $1+1=\underline{\varphi}$}

Questions of what it means to be or become a functional member of society have a long history, but educational ideas and practices are always temporary and reflect the sociocultural and political context in which they appear. Indeed educational theory and practice are subject to discursive disagreements where specific ideas can take a dominant position. In recent decades, it has been argued that educational research has been marginalized in favor of other disciplines, such as brain research and psychological positivism, resulting in an increasing amount of hierarchical classifications and fixed identities (Biesta and Säfström 2011). In this article, I relate this process to neurobiological psychiatry and behaviorism, which is discussed further below. The aim of this article is to argue against a presently emerging instrumental educational practice which I refer to as neurobehaviorism. Doing so, I use some of the ideas formulated by the French philosopher Alain Badiou to highlight the encounter as the place for pedagogical relations to take form. In a wider educational context there is much discussions about what is to be seen as effective in education. Pedagogical encounters, on the other hand, are seen as spaces that hold possibility for the unpredictable and incalculable, and these are often contrasted to 'best practices' based on scientific evidence (e.g. Biesta 2014; O’Donnell 2013). In this article this discussion will be limited to an internationally increasing phenomenon: the expansion of psychiatric diagnoses such as attention deficit hyperactivity disorder (ADHD). ${ }^{1}$

Psychiatric diagnoses such as ADHD is a rapidly growing and globally increasing phenomenon (e.g. Conrad and Bergey 2014; Hinshaw and Scheffler 2014; Lundström 2016). Although individuals challenging normative claims in terms of nurturing and education based on different levels of attention and/or activity-impulsivity is not a new phenomenon, the currently dominant perception regarding this type of behavior is. The present dominant paradigm regarding ADHD is biomedical, where different levels of attention and activity-impulsivity are perceived as neurobiological dys/functions within the brain best managed by means of an individual diagnosis and instrumental pedagogy. Within this realistic paradigm, ADHD is based on objective observations and findings of what is said to be clearly defined facts in nature (Tait 2005; see for example Barkley et al. 2002; Gillberg 2014; Hoogman et al. 2017). This scientific position has been widely challenged, due to the fact that the biomedical discourse is only one of a number of different discourses when it comes to explaining and understanding what in psychiatric terms is defined as ADHD (Graham 2010). On the basis of different philosophical and theoretical approaches, it has been argued that the logic, or rather the illogic (Pérez-Álvarez 2017), behind the diagnosis as a biomedical construct is based on a number of errors in reasoning, not least a circular reasoning that refers the observed behavior back to the socially constructed diagnosis (Tait 2009; Timimi 2017). It has thus been argued that ADHD as a psychiatric diagnosis does nothing but pathologize human differences (Tait 2001). This, in turn, has led to an increasing number of scholars asking parents and practitioners within childcare and education to reconsider the way they approach this controversial topic. And because ADHD is not a medical diagnosis per se (Furman 2008; Meerman et al. 2017), there is an increased need for a relational approach regarding this topic (e.g. Nilsson Sjöberg 2017; Evaldsson

\footnotetext{
${ }^{1}$ Notwithstanding the limited focus (ADHD) of this article, I would argue that the educational alternative proposed in this article may certainly be applied to a more overarching level of discussion of educational theorizing.
} 
2014; Erlandsson and Punzi 2016, 2017; Freeman and Honkasilta 2017; Graham 2010; Honkasilta 2016; Timimi 2017).

The pathologizing of human differences made by psychiatric labelling raises many questions central for educational thinking: Which bodies (and behaviors) are being valued over others? Which professions are the ones that have been given monopoly regarding 'deviant' behaviors? What are the implications of the individualization of problems that emerges in educational contexts in the family or in school? Also defining certain behaviors as a medical problem gives rise to certain interventions that would not otherwise be considered. When the specific discussion about ADHD has come to involve a large number of different academic disciplines, it tends to be less discussed within the field of philosophy and in particular within philosophy of education (Nilsson Sjöberg and Dahlbeck 2017). The ambition of this article is to contribute to this field. And in line with a long philosophical tradition, the overarching leitmotif of this article is to engage with the ontological project that attempts to free from tradition what has been forgotten and solidified by tradition itself. In educational research the 'ontological turn' has received increased attention (Zembylas 2017). The ontological turn includes a recalibration of what forms the basis of analyses. This includes a challenge to the Cartesian heritage that has a fundamental position in science as well as in public opinion in the Western world. In a previous article, and based on the ontological examination of being qua being carried out by Badiou, I have formulated some critical questions and problematized the dominant biomedical model of ADHD. ${ }^{2}$ This work problematizes the epistemological and ontological violence following the individual diagnosis. What should be done on this article is to continue this work and to meet this onto-epistemological act of violence with love on the basis of some aspects found within Badiou's philosophy, here formulated as an educational theory, which goes beyond the individual diagnosis and instrumental pedagogy.

As a result of a globally expanding psychiatrization there is a constant rise in the number of social media forums incorporating public discussions on psychiatric diagnoses. For many years, I have followed what is discussed in some of these social media forums, in particular those primarily focusing on the diagnosis of ADHD. In one of these forums, someone has chosen to post an image of a boy with a piece of chalk in his hand writing the formula $1+1=\boldsymbol{\varepsilon}$ on the school's blackboard. Underneath the image, someone has chosen to write the following comment: "It actually doesn't need to be more difficult than that...". 3 This 'mathematical' formula is discussed in more detail in the second part of this article, in relation to what I choose to refer to as neurobehaviorism. In order to get there, I describe a global development that has brought us the type of diagnostic culture on a 'neuromolecular level' we are now so familiar with.

\section{Diagnostic Culture and a Society of Risk and Control}

Ideas do not exist in a vacuum, but are always in one way or another linked to the development of society. Western societies are characterized by their ever increasing belief in rationality and progress, that future individual and social fulfillment will follow a continuously cumulative process of economic, politic, and scientific progress (Liedman 1999).

\footnotetext{
2 This article is being peer-reviewed at the time of writing.

3 The original comment is written in Swedish: "Det behöver faktiskt inte vara svårare än så...".
} 
However, this optimism in terms of progress is mixed with notions of potential future risks, risks hidden in the future but nevertheless expressed in real terms in the present. The term risk society has been used for describing this phenomenon (Beck 1992). A characteristic of the risk society is that the present is governed by notions concerning the future: "the notyet-event as stimulus to action" (Beck 1992, p. 33). Future potential risks are thus linked to an increasing concern with regard to potential "risk multipliers" (Beck 1992, p. 33). A 'risk multiplier' is someone who has not yet brought about any problem, but is nevertheless constantly perceived as a future threat to society.

'Risk multipliers' have been managed differently throughout history. Let's start with what has been called the Age of Reason. In a number of historical studies, French philosopher and historian Michel Foucault studied how different institutions worked to protect the social order from people who exhibited a 'deviant' behavior. Foucault (1989a) argued that psychiatry and its willingness to classify the abnormal was an institutional construct. Foucault emphasizes that what shapes the basis of psychiatric identities is the intimate relationship between knowledge and power, an act of classification through the use of seemingly objective and instrumental knowledge production. In other words, what Foucault wanted to highlight was psychiatry as a form of repressive control of seemingly fixed identities and personality traits in order to protect the social order. Here, the psychiatrized subject was born. Nevertheless, the disciplinary societies studied by Foucault belong more to previous centuries than to our present time. Whereas Foucault drew our attention to power relations within institutions as a closed system and as arranged systems creating a force of production, Gilles Deleuze emphasis the development of a society of control (Deleuze 1992). The society of control is characterized by "the ultra-rapid free-floating forms of control that replaced the old disciplines operating in the time frame of a closed system" (Deleuze 1992, p. 4). The institutional enclosure that formed the basis of Foucault's historical analyses may be described as molds, whereas the society of control is characterized by instability and constant change, "like a sieve whose mesh will transmute from point to point" (Deleuze 1992, p. 4).

With the technological and scientific-techno-scientific-progress following in the Age of Reason, new power relations took form. These were technologies that could not only be used for social and individual progress, but also for more repressive purposes (Foucault 1989a, b). Through progress in neuroscience and therefore a believed progress in psychopathology, there was a hope that society would get better at managing those identified as mentally ill. In light of this development, human anomalies came to be seen as something inherent in the individual, as neurological dysfunctions preferably managed with the help of psychoactive drugs focused on specific areas of the brain (Bracken and Thomas 2001). This process is characterized by a techno-scientific form of positivism, which seeks to find neurobiological causality behind mental 'disorders' and 'deviant' behaviors. Some researchers have noticed a present global proliferation of neurobiological psychiatry and argued that this expansion resembles a form of neocolonialism (Thomas et al. 2005, p. 27; see also Mills 2014). An example of the expansion of this neurobiological paradigm is found in influential diagnostic psychiatric manuals, such as the Diagnostic and Statistical Manual of Mental Disorders (DSM) - a diagnostic manual that has been characterized by a biological approach since the 1980s and where each new edition of the manual represents an increase in the number of described diagnoses (Davies 2017; Greenberg 2013; Timimi 2014). In other words, what we are dealing with is a significant expansion of psychiatric diagnoses. It is a diagnostic culture (Brinkmann 2016) supported by techno-scientific research and interventions. 
The 'risk-control-diagnosis society' discussed here has not expanded by chance, but constitutes a part of the collective fear dominating our present society. French philosopher Alain Badiou (2010) believes that this is an instance of conservative fear. Conservative fear is a fear of unexpected hazards, a fear of whatever may interfere with the given social order. The present expansion of individual diagnoses is a development corresponding to what Badiou (2009) refers to as bio-materialism. Here, Badiou highlights a post-Cartesian and fragmented view on the subject being managed by a dominant scientism operating under the ideology of human rights. Badiou states that we live in a time dominated by "the strange concoction we're supposed to swallow of a technologized scientism, the crowning glory of which is the visualization of stereoscopic brains in colour" (2011, p. 5), "a sort of scientism stipulating the mind must be naturalized and studied according to the experimental protocols of neurology ..." (2011, p. 118).

Badiou sees this dominant techno-positivist scientism as a way of managing fears concerning potential risks and threats to the current social order. This current social order is governed by the notion that the only thing that matters is what may be considered an object. The process whereby the subject is subsequently reduced into an object supports an identity logic that forms the center of the circular exchange process of the free market (2003, pp. 9; also see 2002, 2017). From this identity logic follows a form of society characterized by fixed hierarchical structures, where each and every one is coded in complex hierarchical systems. Badiou (2009) thus claims that the biopolitics identified by Foucault has been transformed into a form of bioethics. What is beyond our cognitive ability to grasp, Badiou argues, is reduced by totalizing claims of truth, which subsequently open up for various forms of bioethical intervention. This means that being tolerant of everyone's different bodies (and brains), and in particular of the minority body (and brain), is not enough. Instead, based on dominant scientific claims of truth and the democratic principle of human rights, support is given for intervening in 'subordinate' bodies (and brains). Or, as described by Badiou (2009), created in the bombarding turmoil of the universe, the human body (brain) is now the place for scientific dissection.

\section{The Neuromolecular Gaze and a Growing Bio-education}

Controlling human behavior through the human brain has resulted in new forms of expertise in areas such as nurturing, education and mental health (Brinkmann 2016; Kitchen 2017; Rose 2006, 2010; Rose and Abi-Rached 2013, 2014; Timimi 2005, 2014). Starting in the eighteenth century and onwards, and in particular in Europe and North America, knowledge of the brain has continuously come to be intensified and emphasized with regard to mental abnormalities and the moral order of society (Abi-Rached and Rose 2010; Rose and Abi-Rached 2013). In our time, large organizations such as the World Bank and the WHO have indicated a desire for a biopolitics of the brain. As far as "the global burden of brain disease" (Rose and Abi-Rached 2014, p. 4) is concerned, the message is clear: "we need more research, earlier diagnoses, better treatment, and education and training of policy makers and the public about this health problem" (Rose 2006, p. 469). Following the end of the Second World War, there was an increased focus on mental (ill-) health, which was followed by an increased focus on potential threats regarding the economic crisis of the 1990s. This resulted in mental resources or mental capital becoming demanded in a constantly increasing international field of competition-a phenomenon that has not diminished since we entered the twenty-first century. Within this paradigm, the brain increasingly came to be seen as plastic; in other words moldable and open to external 
control. Hence, there was increasing hope in terms of a calculable and predictable future (Rose and Abi-Rached 2013). The neurobiological paradigm was strengthened around the middle of last century, in what has been referred to as the psychopharmacologic revolution (Moncrieff 2008; Rose and Abi-Rached 2013, 2014; Whitaker 2010).

Psychiatric classifications have expanded and spread globally outside psychiatric institutions. Psychiatric diagnoses now cover an increasing number of characteristics previously seen as within the limits of "normality': "No walls are now needed to sustain a lifetime career under the psychiatrist" (Rose 2006, s. 481). The continually expanding psychiatric diagnoses thus form the basis of a medico-instrumental biopolitics. In a Foucauldian way, Nikolas Rose and Joelle Abi-Rached (2010, 2013, 2014) stress the relationship between the ways in which scientific authorities perceive humanity and the subsequent consequences. Out of this neurobiological complex, a neuromolecular gaze has emerged:

This 'neuromolecular gaze' was intrinsically intertwined with the development of psychopharmacology and the rise of drugs for treating people diagnosed with mental illness, first within then outside the walls of the psychiatric hospital. [...] The implications were clear: those who were concerned about the future of our children, and the conduct and welfare of the adults they would become, needed to recognize, and to govern, these processes of shaping and reshaping our plastic brains. (Rose and Abi-Rached 2014, p. 7 and 12)

Rose and Abi-Rached argue that this new way of thinking about people-not least people exhibiting a seemingly abnormal behavior-has led to an epistemological shift, which is interdisciplinary in nature but reductionist in terms of research practices and results. The neurobiological complex is driven by a belief in objective and neutral descriptions of techno-scientific research findings. Neurobiological psychiatry is also performing increasingly earlier screenings of children at risk with the objective of preventing future potential social and economic disasters (Rose 2006). In other words, there are action-focused practices targeted at children and youth in particular, who are pathologized by means of a psychiatric diagnosis and encounter instrumental-medical treatment at an increasingly younger age (Rose 2006, 2010; Rose and Abi-Rached 2013, 2014).

The second part of this article focuses on the expansion of the neurobiological complex and how it has come to support a growing neurobehaviorism, i.e. neurobiologically driven educational practice with a primary objective of visible behavior modification of individuals labelled as 'risk multipliers'. Anyone representing a threat with regard to the constant progress of society must be 'screened to be intervened'. We recognize this approach from positivist psychology, where there is an emphasis on objective behavior modification. An approach supported by brain research and neuropsychiatric diagnoses, where the latter identifies irrational 'symptoms' and the former tries to identify the neurobiological causes behind those symptoms by means of various technological tools. In what follows, I will now discuss how this may be understood in an educational context, while maintaining a focus on the diagnosis of ADHD.

\section{ADHD and Neurobehaviorism}

In DSM-5 the core symptoms of ADHD are defined as deficit in attention and disordered levels of activity-impulsivity. ADHD consists of three different sub-groups and the manifested behavior is heterogeneous. The described symptoms are thus heterogeneous and 
there are individual differences with regard to the extent of the core symptoms. Using a medical term, ADHD is frequently also comorbid with other diagnoses and conditions. DSM-5 furthermore states that there are no biological markers used for diagnosis. Instead, the diagnosis is made on the basis of a set of criteria. If a person meets a certain amount of those criteria, the described 'symptoms' turn into a dysfunctional mode/(neuro)psychiatric condition (APA 2013).

ADHD is one of the most studied psychiatric diagnoses for children and adolescents. It was not until the late eighteenth century that children and youths with challenging levels of attention and activity came to be seen as a medical, and later psychiatric, problem. This was at a time when agricultural communities were converted into industrial societies at an increasing rate, and where there was a subsequent need for forces of production. As a result of the socio-economic and political changes brought on by the concept of production and the optimism related to progress, difficult children were seen as an increasingly significant 'risk' society needed to handle (Foley 2014; Mayes and Rafalovich 2007; Smith 2010; Taylor 2011).

A common discourse with regard to ADHD is the risk discourse (Bailey 2010; Thodelius and Lundälv 2017). Here, the actual set of symptoms of 'ADHD' are said to constitute a (future) risk for both the individual and society. The article "We Need to Pay More Attention to ADHD—Early Efforts Reduce Suffering" (Fernell et al. 2014) represents a clear and striking example of this risk discourse. It is emphasized that we are now living in a more cognitively demanding society, which has consequences for many children and youths with ADHD, as they are not seen as living up to expected performance levels at school. It is also stated that:

Problems related to children with defiance syndrome acting out are found in many children already in pre-school [...] and conduct disorders in adolescence have been shown to represent an increased risk of drug and alcohol abuse and criminal behavior in adulthood [...]. (Fernell et al. 2014, p. 1, author's translation) ${ }^{4}$

The authors then refer to studies said to demonstrate structural and functional differences in the brain, followed by:

For many, medication results in a significant improvement in terms of symptoms. The most common substance is methylphenidate, which belongs to the group of central nervous system stimulant drugs. Long-acting amphetamine-based drugs have also become available. (Fernell et al. 2014, p. 3, author's translation) ${ }^{5}$

There is a UN report on the global situation regarding the use and proliferation of psychoactive drugs. With regard to the drug methylphenidate (mentioned in the quote above), the report demonstrates a significant global increase, which is explained as a result of the

\footnotetext{
4 References in this quote have been excluded in order to minimize possible confusion.

5 MD Charles Bradley is said to be the first to treat children and youths with the amphetamine-based drug Benzedrine, which is a significant act in relation to contemporary medical treatment of ADHD. This was done in 1937 when Bradley presented his theory on the corrective effect of this drug on the central nervous system, which also turned out having some 'therapeutic' effects on children and youths exhibiting problematic behaviors. The 30 children and youths who were included in the study showed no deviations in terms of IQ and the majority experienced school-related problems: "The most striking change in behavior during the week on Benzedrine [amphetamine] therapy occurred in the school activities. [...] Fourteen children responded in spectacular fashion" (Bradley 1937, p. 578). The modification was met with joy from teachers and other caregivers (Baumeister et al. 2012; Mayes and Rafalovich 2007).
} 
increasing number of diagnoses. The UN is concerned about this increase (UN 2014, p. 37-38). In a Swedish context, the National Board of Health and Welfare (Socialstyrelsen 2015) reports that the prescription of ADHD drugs has continued to increase, just like in previous years. Boys and girls aged 10-17 are the groups with the highest proportion of existing users in the population. Approximately five percent of boys aged 10-17 are medicated. This means that the prescription of boys is now said to border the estimated prevalence of ADHD.

There is only limited space in an article and I do not believe that more examples are needed, as the picture is clear as to which 'treatment' - or educational intervention-is the one used for children and youths, in particular boys between the ages of 10 and 17, exhibiting an ADHD profile. Alongside the discourse emphasizing ADHD as a risk, a discourse emphasizing the danger of medical treatment has also been established (Thodelius and Lundälv 2017). This discourse is based on the fact that there are no known studies demonstrating any long-term positive effects as a result of medical treatment. It is furthermore argued that short-term effects must be put in relation to the substantial side effects resulting from the use of stimulants and other psychoactive drugs (see SBU 2013). Instead of highlighting the physiological and mental side effects resulting from using drugs for treating ADHD (as this is done elsewhere), my aim is to argue against a presently emerging instrumental educational practice I refer to as neurobehaviorism. This is an educational model looking for techno-scientific evidence in research in order to legitimize visible modification of behavior by means of neuromolecular intervention.

This educational model attempts to categorize and standardize the child at risk in accordance with dominant interests in society by chemically altering presumed neuromolecular dysfunctions. This concerns modification of visible behaviors derived from invisible neurological dysfunctions that have as of yet not been made visible. The axiom that forms the basis of a neurobehavioristic educational model could be summarized as two differences meeting on the basis that a certain 'third' - a stipulated and calculable resultis to follow. The individual diagnosis thus results in an educational standardized recipe. Below, I present a pedagogical alternative to this form of neurobehaviorism based on the 'mathematical' formula $1+1=\underline{\mathbf{Q}}$. As mentioned in the introduction, this is done with the help of the French philosopher Alain Badiou, which is why the article now takes a more pronounced philosophical turn.

\section{Toward a Militant Pedagogy in the Name of Love}

\section{Being, the Empty Set and Generic Truths}

In a philosophical sense being is that which is, as opposed to that which is not. Ontological examinations of being qua being have a long tradition in philosophy. Alongside a long philosophical tradition of thought, Badiou argues that what we refer to as being has subsequent implications in the sense that our thoughts about being are what actually constitute it. Badiou claims that the last person to carry out a thorough ontological analysis of being was Martin Heidegger in Being and Time (1927/2008). As highlighted by Badiou in his Being and Event (2005), it is time for an updated ontological reexamination of being qua being. Badiou sees it as his main task to release from philosophical tradition what had been locked and solidified by philosophy itself, and two major themes are the Cartesian split between subject-object/mind-body, and the notion of truth. As mentioned above, 
metaphysical analyses have a long tradition. Today, however, metaphysical analyses serve an important function alongside the forgetfulness of being found within the modern concept of progress. In this text, the term neurobehaviorism falls within the framework of a clear educational model in the wake of the modern concept of progress. To recapitulate, neurobehaviorism is based on the notion of the diagnosis as an educational axiom in the hope and belief that two 'differences' coming together will lead to a calculable result, to a predetermined and desirable 'third'. This assumption is rejected by Badiou, as he argues that the definitive answer is always uncertain and that it is never possible to calculate situations in advance. He finds the basis for this in mathematics, and more specifically in mathematical set theory.

A foundational claim for Badiou is that 'If the one is not, nothing is'. Because if something is presented as multiple, Badiou states, it must imply that being is not one. "For if being is one, then one must posit that what is not one, the multiple, is not" (Badiou 2005, p. 25, emphasis in original). For Badiou mathematics is the only language that can make a pure description of being. Therefore, Badiou's (2005) method is deductive drawing on some principles of mathematical set theory. As a materialist philosopher arguing from the standpoint of set theory, Badiou states that being is composed of an infinite amount of different elements - multiplicities - organized into different sets. The very basics in set theory are that $a$ set is any collection of elements, or objects, which could be 'counted as one'. Sets always have to be made. If a set can be made up of every element/object that can be counted as one, this means that sets are construable. Further, two sets can be equal, if all the elements of, let's say set $a$, also is what constitutes set $\beta$. These two sets are then identical and equal to each other. In any case where two sets are not equal but share certain elements in common, a given set is a subset of another. And a subset is always being made up of other subsets ad infinitum. This is so because when constructing a (new) set there always follows a (new) empty set, which is not graspable. This empty set is the null set. The empty set is void, it is nothingness ... before a new set is made up of this empty set and what we think of as a truth is being presented.

According to the above logic, being is multiple of multiples, whose substance is void. Indeed being is made up of constructible sets, always implying a null set. On the basis of set theory, being qua being is said to be homogeneous in such a way that it only includes pure multiplicity containing an infinite alterity that is absolutely neutral in its nothingness. But if being is multiple, how can anything then be counted as one? For an answer to this, Badiou turns to the structure of a situation: "every situation admits its own particular operator of the count-as-one" (2005, p. 26). Being as pure multiplicity presents itself in accordance with the structure of each specific situation. A situation is where a multiple and a regime of the count-as-one (a structure) results in a presented multiplicity that can be counted as one. There is nothing apart from situations, and what is presence ('being there') is not to confuse with what is presented. The latter implies an act of 'onto-epistemological violence' made by the presentation of the presented. Being as one is always a retroactive fiction made by the presentation of an otherwise pure multiplicity that presents itself by the given structure of a situation.

What Badiou $(2002,2003,2005)$ names the event is what is presented in various situations by specific truth procedures. ${ }^{6}$ The event is immanent to a situation, but is not part of

\footnotetext{
${ }^{6}$ Badiou highlights four different generic truth procedures in particular: politics, art, science and love. So far, I have focused on the scientific paradigm, which is dominant with regard to the diagnosis of ADHD. Below, I focus on the generic truths procedures of love as an educational theory and practice.
} 
it. The event exists only as a void to the state of the situation. Badiou argues that a truth emerges when a situation becomes an event and when one commits, or show fidelity, to the truth of the event. The event is not possible to be fully explained, as it is always excessive in relation to the situation in which it is created. The event surprises being, it is anarchistic and emerges from being in a way impossible to predict. The event passes by as quickly as it appears, while leaving traces forming the basis of the creation of what we refer to as truth. What we may do with regard to the event is to grab hold of it-being faithful, showing fidelity to the event-in order to become a subject to truth. Badiou claims that it is not until then that we go from acting on the level of animals to becoming subjects in the world.

Accordingly, Badiou concludes that being always goes beyond the appearance of the 'thing' about which we want to possess knowledge. Being is the incurable uniqueness of indifference; the moment before the creation of distinct elements. The subject is void, never in itself fully explainable, the subject as a process of becoming. "A subject is also a finite local configuration of a generic procedure" and "[i]t can thus be said that a subject occurs or is revealed locally" (Badiou 2005, p. 555). It is right in the moment of the split between being as pure multiplicity and presentation that marks the subject's existence or non-existence. Putting it differently, mathematical set theory used by Badiou implies that there is always a set evading totalitarian knowledge practices. The empty set may never be categorized and named in a system. The empty set always evades epistemological practices. Through complex relationships, being as indifference always manifests itself as a difference, as objects that to varying degrees and in one way or another differ from other objects. What we accept as truth is thus a generic procedure, which is to say that it is possible to construct all of the sets that constitute being, but not the empty set. But according to Badiou, this does not mean that there are no totalizing knowledge practices at work. On the contrary, totalitarian practices exist to a great extent and in many different forms. The truths we use for navigating through life, and which represent public opinion, are among other things based on dominant scientific claims of truth that constitute a representation of what is presented in different situations. Instead, what Badious offers is the formula mathematics = ontology, a formula able to "deconstructs any one-effect; it is faithful to the nonbeing of the one ..." (Badiou 2005, p. 33). His axiom of work is a way to allow pure multiplicity to remain without being reduced to one. Thereby, the main purpose of Badiou's ontological examination is to think being qua being without 'the One'. Because if 'the One' does not exists, then neither can 'the Other'.

\section{Apples, Pears and Snails}

Badiou (2002) stresses that what is dominant at the moment - the state of the order-takes the form of 'the One', a power relation that always puts 'the Other' in being. Thus, classification and categorization become a generic truth procedure where the pure and neutral multiplicity of being is forced into hierarchically coded systems. From the state of the order, second class citizens are created by being framed as a negation of an abstract, albeit dominant, concept of humanity; an organization of the world at the level of 'the One'.

Badiou (2015) uses the fruit bowl as an example to better explain this ongoing but constantly evolving classifying practice. The fruit bowl acts as a definition and demarcation vis-à-vis the correct: what is desirable compared to that which does not belong in a fruit bowl. In normal cases, we are accustomed to only finding edible fruit in a fruit bowl. If the edible fruit is mixed up with, for instance, snails, then the fruit bowl still works as the definable order that excludes the unwanted from its definition. But what happens if the 
fruit bowl is removed so that apples and pears are mixed in a pile together with snails? The answer, as suggested above, is that every set is neutral at the level of being. However, 'the One' is always made into something desirable and well-defined, thereby resulting in 'the Other' becoming a negation of the well-defined set. Organizing and naming different sets is sometimes difficult, which is why technological innovations are used to determine the existence of different sets. If apples and pears are desirable, then people are disgusted by snails-especially if they are found in people's fruit bowls, or in their gardens-which is why they make sure that there are no more snails than they can handle. Therefore, they look for effective strategies, not infrequently chemical-technical products that efficiently eradicate the snails.

The neuropsychiatric diagnosis of ADHD is one example of such classifying and excluding definition. The act of diagnosing is a naming process that excludes the less desirable by means of definition, by putting it in relation to the desirable. In the analogy above, ADHD is to be seen as a risky snail threatening the nice fruit in the bowl. Staying with the analogy, the dominant approach in our time is to dissect the snail—the 'risk multiplier' —at the smallest possible (neuromolecular) level so that it may be transformed into an apple or a pear. As far as the diagnosis of ADHD is concerned no biological markers have been identified, even though a recipe has been developed. A recipe that targets visible (and in some situations less appropriate) behavior and is expected to lead to a certain result. What is written on the recipe is neurobehaviorism in chemical form licensed by the classificatory naming process that leads to the individual diagnosis.

\section{$1+1$ On the Scene of Love $=\underline{\varphi}$}

As we have seen above, the psychiatric diagnosis is an act of classification and a naming process tantamount to an act of violence on the subject. ${ }^{7}$ This is due to the fact that we are all equal at the level of being. At the level of being, difference exists in its indifference. The fact that being is absolutely neutral means that the subject only belongs to its own indifference. If we now look at the formula $1+1=\underline{\boldsymbol{e}}$ it is about two differences equal to each other in their indifference. Nevertheless, the sum is not possible to calculate in advance. The sum is not 2 . The sum is not a predetermined 'third'. The fact is that there are examples of 'one plus one' that do not equal two, because at an ontological level, the value of each 'one' is indistinguishable (Badiou 2008). That is why $1+1$ at the level of being is an encounter that does not result in a fixed sum possible to calculate in advance.

Now that we have seen that difference at the level of being is non-hierarchical indifference, we still need to find out what the heart $(\boldsymbol{(})$ in the formula represents. The heart that is the sum when two indifferences are added to one another. The heart that completes the 'mathematical' formula published on a forum for people diagnosed with ADHD. The heart that is underlined by the boy in the picture. The heart as a symbol of love. Let us take a closer look at what love means for Badiou. For Badiou (2012), it is clear that love goes beyond sentimentality and sexuality. Love is a meeting, an encounter. An encounter can take place everywhere and may come to involve each and every one of us as an erupting event: "The event is that hazardous supplement we call an encounter" (Badiou 2008, p. 188). For Badiou this is the universality of love. The actual event constitutes the spacetime

\footnotetext{
7 And it appears to be both an onto-epistemological and a pharmaceutical act of violence.
} 
where an encounter between two indifferences takes place. The event does not prove anything, it is only "pure beginning" (Badiou 2003, p. 49).

Badiou (2012; see also 2010) claims that love is something that needs to be reinvented since we live in times where love is under threat from a variety of directions. We live under constant development, which is why the concept of love also needs to be developed: "Love is the hidden power within the catastrophe" (Badiou, 2012, p. 83). What now represents a threat to love is conservative fear: a fear of not knowing, a fear of that without a name, a fear of taking risks and not being efficient enough. Our concept of love as it has evolved is only love formulated by and in the name of 'the One': a dominant and, I would argue, fearful and oppressive love. As described above, it seems as if the love 'we' (we: the dominant order) show children and youths who challenge the state of the order, is a love of good intentions, but nonetheless a love that does not consist of anything but an act of violence. It is violent love. And we see a link to the aforementioned 'risk multipliers'. There are to be no risks in the encounter with the child at risk. According to Badiou an encounter is always uncertain and the result is impossible to calculate in advance. It is an encounter between 'the Two' that does not generate a fixed and final 'third'. Love is generic, but uncertain:

[Love] is a construction, a life that is being made, no longer from the perspective of One but from the perspective of Two. And that is what I have called a "Two scene".

(Badiou 2012, p. 29)

On the scene of love, the Two scene, we find 'the Two'. Two subjects that in their own indifference are pure and neutral multiplicity, but through the event start to exist as two differences occupied with performing a procedure of truth. When two differences enter the Two scene of love, they have to choose which truth to be produced. The choice is either to see the world on the basis of 'the Two' or at the level of 'One'. Badiou sees the former as true love, as it has been shown above that the latter is tantamount to a violent act on the subject. The true enemy of love is selfishness, which emphasizes identity over difference (Badiou 2012, p. 60). An encounter at the level of 'Two'-instead of at the level of 'One' - creates a specific form of truth, a truth where not only 'the One' but 'the Two' are the active parties in a situation. When 'the Two' enter the scene of love, they must face the world on the basis of difference, and this is always a risky and uncertain encounter. Such an encounter does not represent an experience of the other, but constitutes an event that remains relatively unclear. Love, in other words, is a construct rather than an experience, a joint examination of the world on the basis of 'the Two' instead of the dominance of 'the One': "Love is an enquiry into the world from the vantage point of the Two, and not at all an enquiry about each term of the Two about the other" (Badiou 2008, p. 193). In light of the event, 'the Two' enter the scene of love in a meeting where they become subjects of love. Together, they look upon the world through the prism of 'the Two' and a new world is born beyond both 'the One' and 'the Other': "Love is always the possibility of being present at the birth of the world" (Badiou 2012, p. 26).

Badiou furthermore states that the numerical schema of the amorous procedure is "One, Two, Infinity" (2008, p. 189, emphasis in original). Through the numerical schema of love, the meeting of 'the Two' breaks up 'the One' so that they may experience the infinity of the situation together. Hence, love may never be reduced to any form of predetermined law. Becoming a true 'loving' subject to the event represents nothing less than having the courage to face a difference, despite the fact that precisely this difference may seem frightening and difficult to handle. An educational model built on love rebels against the order, is opposed to the law: "There is no law of love" (Badiou 2012, p. 79). So the heart in the formula analyzed represents uncertainty, an adventure of 'the Two'. This is a possible 
conclusion, as Badiou sees love as an adventure with an uncertain destination. A love trip born into the world that does not follow predetermined laws: "[Love] is an event that can't be predicted or calculated in terms of the world's laws" (Badiou 2012, p. 31). An educational model based on love goes beyond a fixed and final subject, goes beyond instrumental and standardized encounters, beyond hierarchical classifications and codified categories, and therefore beyond the individual psychiatric diagnosis.

\section{A Militant Pedagogy in the Name of Love}

The fact that love is a generic truth procedure means that it is also possible to reinvent new subjects; to bring the otherwise non-existent to life (Badiou 2003, 2009, 2012). How could this be done? Badiou brings up the notion that today we have to deal with the assumption that what benefits the majority is good for everyone (Badiou 2015, p. 24). It is at this time, when love is besieged by specific truth procedures that in advance attempt to rationalize the otherwise uncertain destination of a love encounter, a time of 'violent love', that Badiou is looking for a new heroic figure. What he is looking for is this someone with the courage to stand up for love instead of subordinate dominant claims of truth. Someone with the courage to stand up to ontological violence. Someone with the courage to be true to the particularity of the event and becoming that someone who grabs ahold of the traces following the event and thus entering history-becoming infinite. To describe this heroic act, Badiou uses the word militant. As described in the introduction to Philosophy for Militants (2015), the term militant should not be understood as marching military boots or massive arsenals of weapons. Instead, the term should be understood on the basis of its etymological meaning; that is, someone who walks many miles, a mile-goer: "We could thus say that a militant, simply put, is somebody who not only talks the talk but also walks the walk, or who goes the full mile" (Badiou 2015, p. xix). The term miles may also be traced back to medieval Latin and thus becoming synonymous with knight-errand: the militant as knighterrant becoming a less violent alternative to the warrior and the soldier, two otherwise dominant militant figures throughout history.

When it comes to the love encounter, what Badiou refers to as a point is where the event appears and presents us with a choice. A place where we all, in order to be true to love, must answer: "I accept this chance, want it and take it on board" (Badiou 2012, p. 50). In Badiou's Saint Paul: The Foundation of Universalism (2003), it is emphasized that only the one who dares stand up to the order of world may become a subject. To become a subject through a love encounter thus means to be faithful to the event, and only the person having the courage to be faithful to what emerges from the event becomes a subject. Badiou believes that anything else is acting on the basis of the animal side of man. Love is nothing mysterious, nor is it a miracle that in itself leads to what is right. On the contrary, love requires hard work: "There is a work of love: it is not simply a miracle. [...] You must think act and change" (Badiou 2012, p. 81). Simply put, whoever is militant in the name of love shows fidelity to the particularity of the encounter. The alternative is to distance oneself from the encounter and let the event pass by without a (militant) intervention and thus maintaining the world at the level of 'One'; letting the 'ontological violence' pass by: "Either one participates in it, declaring the founding event and drawing its consequences, or one remains foreign to it" (Badiou 2003, p. 21).

Here, an example may serve to clarify: The idea that ADHD is a "disorder of the brain" (e.g. NIMH 2016) opens up for certain professions such as (neuro)psychiatrists being perceived as experts to educational practices, even if they do not engage in the child's everyday life and in all those specific situations where 'ADHD' manifests itself. And by the 
process of psychiatrization-i.e. techno-scientific onto-epistemological violence-the diagnosed person is being reduced to a fragmented subject - an object—-that needs to, by any means, be hindered from risking society's progress and thus to protect the social order. Formulated as an individual diagnosis, ADHD decontextualizes and reduces what it means to be a human being and places the 'dysfunction' within the diagnosed person. In educational theorizing, such a perspective could be termed punctual (see von Wright 2006). The relation between subjects will here be put aside while waiting for the diagnosis-external professionals/experts - to provide answers concerning the child's putative biogenetic and neurological dysfunctions. The individual diagnosis as an educational axiom hinders educators/caregivers from seeing the potential found in every particular encounter which follows from the specific structure of each and every situation. This means that anyone acting militantly in the name of love possesses an 'infinite force' (infinity is here based on the fidelity to an event that writes itself into history) by choosing to be faithful to situations where a certain behavior (e.g. 'ADHD') manifests itself instead of accepting 'ADHD' as a preexisting individual dysfunction within the diagnosed person. Acting militantly in the name of love is to have the courage to say no to the individual diagnosis, which is being made from the perspective of 'One', and instead on the 'Two scene' (the encounter) constructing a new truth that is based upon the perspective of 'Two'. By the former the current state of order will be maintained at the level of 'One' (and only) and the diagnosed person will be nothing but 'the Other' that needs to be included, or forced, into this dominant state of order (e.g. in a school where the activities is not made available for everybody ...), or sacrificed as 'the Other' that the majority may feel sorry for.

If an individual diagnosis is equivalent to a fragmented subject and fixed identity, then this is tantamount to an educational act equivalent to a murder-or at least a castration-of the subject. Such violence is a far cry from the heroic figure described by Badiou. Unlike the heroic and militant figure described by Badiou, the one that uses violence by making the individual psychiatric diagnosis an educational axiom is a figure who accepts a system that codifies human (in)differences in a hierarchical order. In such a system, there can only be superiors and subordinates. The one who believes in the general law, the standardized diagnostic manual, the individual diagnosis, is acting in the name of death. The opposite is to affirm life, to emphasize life over death (Badiou 2003). On the Two scene of love, we have 'the Two', whereas according to Badiou, the position of 'the Other' (as the subordinate number two) is nothing but a fallacy that needs to be refuted. It is about not taking the claims of truth of 'the One' for granted, but having the courage to militantly stand up and affirm life; to have the courage to think beyond the individual diagnosis-in this article exemplified by the diagnosis of ADHD.

Returning to the 'mathematical' formula, the sum of $1+1$ is not a pre-determined result. $1+1$ is always more than that, just like it is highlighted by the boy in the picture. For the boy, the sum is symbolized by an underlined heart: $\boldsymbol{\imath}$. The heart as the symbol of love. Love as an exploration of the world on the basis of 'Two' and not the level of 'One'. To this picture someone made the comment: "It actually doesn't need to be more difficult than that...".

\section{Concluding Discussion}

Ideas do not exist in a vacuum, but are always linked to the time and space in which they are formed. Children and youths who, through complex relationships under local stipulations, 
have come to appear and be identified on a 'neuromolecular' level are nothing but a sign of the times. Our present time is characteristic by a classificatory and techno-scientific paradigm that has led to the construct of ADHD. Even if the dominant biomedical model is only one of a number of different models, it has expended into areas such as nurturing, education, and mental health. The biopsychiatric model and its expanding borders have not escaped criticism and it is stressed that "many diagnoses, especially those 'on the borders', are judgements of social deviance or problems of living that have no place in psychiatry" (Rose 2006, p. 477). Furthermore:

we need to react with caution to the claims about the 'burden of brain disorder' and the language within which they are framed. We know that these claims are in part rhetorical: they are used to make appeals to politicians and others about the urgency of funding research and the scale of the problem. But the framing of the issues in this way is not innocent. (Rose and Abi-Rached 2014, p. 17)

The neurobiological model may lead us to believe that there are pure and clearly distinguished facts behind the diagnosis. Escaping this neurobiological 'bind' of ADHD is not easy, as the diagnosis is based on a circular logic that leads us nowhere but back to the right of (neuro)psychiatry to control the defined group. However, it is emphasized that not least parents, teachers, and mental health practitioners should reconsider the approach that has now come to dominate how we perceive children and youths exhibiting a behavior profile corresponding to the criteria of ADHD. Furthermore, diagnoses and categories mystify matters, which leads to a reduced number of ways in which to look upon human existence. Diagnoses as categories bring together unique individuals under the same conceptual umbrella, which in turn overlooks the uniqueness of each individual subject. Putting it differently, the neuropsychiatric vocabulary and diagnosis as a category could lead to young people diagnosed with ADHD not having their individual needs seen and satisfied. Hence, there is a need in educational contexts to look beyond the instrumental educational model following the diagnosis of ADHD, to instead draw attention to and hold on to the particular situations where 'ADHD' is manifested.

A leitmotif of this article has been to highlight an instrumental pedagogy at a neuromolecular level-chemical neurobehaviorism-incorporating an increasing number of children and youths (and adults) around the world labelled as having ADHD. This group of people fall within the framework of the bioethics that has become a part of a growing 'riskcontrol-diagnosis society'. Potential 'risk multipliers' are here facing an act of onto-epistemological violence and a subsequent murder, or at least a castration, of the subject. Against this, the aim of this article has been to formulate a less violent educational option: one that emphasizes love over violence. This educational alternative seeks to place the encounter at center stage. The encounter as a 'Two scene' of love where two indifferences presented as differences to each other have the possibility of exploring the world on the basis of 'Two' instead of adopting the perspective of (the dominant) 'One'. It is an educational model that requires a militant stance: an active participation in each particular situation where it becomes possible to open up for the appearance of that which does not yet exist. A pedagogical approach driven by the courage not to allow oneself to be governed by a conservative fear in the meeting with the 'at risk child'; driven by the courage to follow up what is otherwise seen as a threat to the current state of the order by facing the future on the basis of 'Two' instead of 'One'. This is an educational model that does not accept a passive role when so-called experts enter the educational arena, experts who by means of a totalitarian reductionism transform otherwise undefinable conditions into an individual diagnosis. Behaviors that are now seen as individual, neurological dysfunctions are in other words an 
effect of the local stipulations of complex relationships. This also means that 'ADHD' does not exist beyond the particular, but comes into existence in different ways in each specific situation. Situations that are impossible to calculate in advance.

The educational model I here suggest is under threat from another paradigm where only that which matters - the named, the object-exists and must exist in order to keep society going. As mentioned above, this relativizing identity logic is tantamount to an act of ontological violence on being, which leads individuals to fixed identities codified in hierarchical orders. When 'the One' seeks a totalizing approach, identity is placed before difference, thereby leading to the openness lurking beyond the diagnosis becoming a threat to this exercise of control. Unlike instrumental behavior modification at the neuromolecular level, a militant pedagogy in the name of love does not shy away from the uncertain, but sees the encounter as a potential for creating something new. It is on the Two scene of love that change takes place. That is why a militant pedagogy in the name of love looks at the formula $1+1=\boldsymbol{\varepsilon}$ and thinks: It actually doesn't need to be more difficult than that...!

\section{Compliance with Ethical Standards}

Conflict of interest The author declares no conflict of interest.

Open Access This article is distributed under the terms of the Creative Commons Attribution 4.0 International License (http://creativecommons.org/licenses/by/4.0/), which permits unrestricted use, distribution, and reproduction in any medium, provided you give appropriate credit to the original author(s) and the source, provide a link to the Creative Commons license, and indicate if changes were made.

\section{References}

Abi-Rached, Joelle M., and Nikolas Rose. 2010. The Birth of the Neuromolecular Gaze. History of the Human Sciences 23(1): 11-36.

APA. 2013. Diagnostic and Statistical Manual of Mental Disorders (DSM-5), 5th ed. Washington, DC: American Psychiatric Association.

Badiou, Alain. 2002. Ethics-An Essay on the Understanding of Evil. London: Verso.

Badiou, Alain. 2003. Saint Paul. The Foundation of Universalism. Stanford, CA: Stanford University Press.

Badiou, Alain. 2005. Being and Event. London: Continuum.

Badiou, Alain. 2008. Conditions. London: Continuum.

Badiou, Alain. 2009. Logics of Worlds. London: Continuum.

Badiou, Alain. 2010. The Meaning of Sarkozy. London: Verso.

Badiou, Alain. 2011. Second Manifesto for Philosophy. Cambridge: Polity.

Badiou, Alain. 2012. In Praise of Love. London: Serpent's Tail.

Badiou, Alain. 2015. Philosophy for Militants. London: Verso.

Badiou, Alain. 2017. The True Life. Cambridge: Polity Press.

Bailey, Simon. 2010. The DSM and the Dangerous School Child. International Journal of Inclusive Education 14(6): 581-592. https://doi.org/10.1080/13603110802527961.

Barkley, Russel A., et al. 2002. International Consensus Statement on ADHD. Clinical Child and Family Psychology Review 5(2): 89-111.

Baumeister, Alan A., Kristopher Henderson, Joni Lee Pow, and Claire Advokat. 2012. The Early History of the Neuroscience of Attention-Deficit/Hyperactivity Disorder. Journal of the History of the Neurosciences 21(3): 263-279.

Beck, Ulrich. 1992. Risk Society. Towards a New Modernity. London: Sage.

Biesta, Gert J.J. 2014. The Beautiful Risk of Education. Boulder: Paradigm Publishers.

Biesta, Gert, and Carl Anders Säfström. 2011. Ett manifest för pedagogik [A Manifesto for Education]. Utbildning \& Demokrati - tidskrift för didaktik och utbildningspolitik 20(3): 83-95.

Bracken, Patrick, and Philip Thomas. 2001. Postpsychiatry: A New Direction for Mental Health. BMJ 322: 724-727. 
Bradley, Charles. 1937. The Behavior of Children Receiving Benzedrine. American Journal of Psychiatry 94(3): 577-585.

Brinkmann, Svend. 2016. Diagnostic Cultures: A Cultural Approach to the Pathologization of Modern Life. New York, NY: Routledge.

Conrad, Peter, and Meredith R. Bergey. 2014. The Impending Globalization of ADHD: Notes on the Expansion and Growth of Medicalized Disorder. Social Science and Medicine 122: 31-43.

Davies, James. 2017. How Voting and Consensus Created the Diagnostic and Statistical Manual of Mental Disorders (DSM-III). Anthropology \& Medicine 24(1): 32-46. https://doi.org/10.1080/13648 470.2016.1226684.

Deleuze, Gilles. 1992. Postscript on the Societies of Control. The MIT Press 59: 3-7.

Erlandsson, Soly, and Elisabeth Punzi. 2016. Challenging the ADHD Consensus. International Journal of Qualitative Studies on Health and Well-being 11: 1-2. https://doi.org/10.3402/qhw.v11.31124.

Erlandsson, Soly, and Elisabeth Punzi. 2017. A Biased ADHD Discourse Ignores Human Uniqueness. International Journal of Qualitative Studies on Health and Well-being. https://doi.org/10.1080/17482 631.2017.1319584.

Evaldsson, Ann-Carita. 2014. Doing Being Boys with ADHD: Category Memberships and Differences in SEN Classroom Practices. Emotional and Behavioural Difficulties 19(3): 266-283.

Fernell, Elisabeth, Björn Kadesjö, Lena Nylander, and Christopher Gillberg. 2014. ADHD bör uppmärksammas mer - tidiga insatser spar lidande [ADHD Should get more Attention-Early Interventions Save Suffering]. Läkartidningen 111: 1-5.

Foley, Paul Bernard. 2014. Sons and Daughters Beyond Your Control: Episodes in the Prehistory of Attention Deficit/Hyperactivity Syndrome. ADHD Attention Deficit Hyperactivity Disorder 6(3): 125-151. https://doi.org/10.1007/s12402-014-0137-y.

Freeman, Justin E., and Juho M. Honkasilta. 2017. Dictating the Boundaries of ab/Normality: A Critical Discourse Analysis of the Diagnostic Criteria for Attention Deficit Hyperactivity Disorder and Hyperkinetic Disorder. Disability \& Society 32(4): 565-588. https://doi.org/10.1080/09687599.2017.12968 19.

Foucault, Michel. 1989a. Madness and Civilization. A History of Insanity in the Age of Reason. London: Routledge.

Foucault, Michel. 1989b. The Birth of the Clinic. An Archaeology of Medical Perception. London: Routledge.

Furman, Lydia M. 2008. Attention-Deficit Hyperactivity Disorder (ADHD): Does New Research Support Old Concepts? Journal of Child Neurology 23(7): 775-784.

Gillberg, Christopher. 2014. ADHD and its Many Associated Problems. Oxford: Oxford University Press.

Graham, Linda J. 2010. Teaching ADHD? In (De)Constructing ADHD Critical Guidance for Teachers and Teachers Educators. ed. Linda J. Graham, 1-19. New York, NY: Peter Lang.

Greenberg, Gary. 2013. The Book of Woe. The DSM and the Unmaking of Psychiatry. New York: Blue Rider Press.

Heidegger, Martin. 1927/2008. Being and Time. New York, NY: Harper \& Row, Publishers, Inc.

Hinshaw, Stephen P., and Richard M. Scheffler. 2014. The ADHD Ex-plosion. Myths, Medication, Money and Today's Push for Performance. New York, NY: Oxford Uni-versity Press.

Honkasilta, Juho. 2016. Voices Behind and Beyond the Label: The Master Narrative of ADHD (De)constructed by Diagnosed Children and Their Parents. Doctoral thesis, Jyväskylä Studies in Education, Psychology and Social Research 553. Jyväskylä: Jyväskylä University Printing House.

Hoogman, Martine, et al. 2017. Subcortical Brain Volume Differences in Participants with Attention Deficit Hyperactivity Disorder in Children and Adults: A Cross-Sectional Mega-Analysis. The Lancet. https:// doi.org/10.1016/S2215-0366(17)30049-4.

Kitchen, William H. 2017. Philosophical Reflections on Neuroscience and Education. London: Bloomsbury.

Liedman, Sven-Eric. 1999. I skuggan av framtiden. Modernitetens idéhistoria [In Shadow of the Future. History of Modernity]. Stockholm: Bonnier.

Lundström, Tommy. 2016. ADHD; Om förekomst, ökning och konsekvenserna för social barnavård [ADHD; Prevalence and the Consequences for Social Child Care]. Socionomen 1: 18-31.

Mayes, Rick, and Adam Rafalovich. 2007. Suffer the Restless Children: The Evolution of ADHD and Paediatric Stimulant Use, 1900-80. History of Psychiatry 18(4): 435-457.

Mills, China. 2014. Decolonizing Global Mental Health: The Psychiatrization of the Majority World. London: Routledge.

Moncrieff, Joanna. 2008. The Myth of the Chemical Cure. A Critique of Psychiatric Drug Treatment. Basingstoke: Palgrave Macmillan.

National Institute of Mental Health [NIMH]. 2016. ADHD. https://www.nimh.nih.gov/health/topics/atten tion-deficit-hyperactivity-disorder-adhd/index.shtml. Accessed 12 September 2017. 
Nilsson Sjöberg, Mattias. 2017. (Un)becoming dysfunctional: ADHD and how matter comes to matter. International Journal of Inclusive Education 21(6): 602-615. https://doi.org/10.1080/13603116.20161 251977.

Nilsson Sjöberg, Mattias, and Johan Dahlbeck. 2017. The inadequacy of ADHD: A philosophical contribution. Emotional and Behavioural Difficulties. https://doi.org/10.1080/13632752.2017.1361709.

O'Donnell, Aislinn. 2013. Unpredictability, Transformation, and the Pedagogical Encounter: Reflections on "What is Effective" in Education. Educational Theory 63(3): 265-282.

Pérez-Álvarez, Marino. 2017. The Four Causes of ADHD: Aristotle in the Classroom. Frontiers in Psychology. https://doi.org/10.3389/fpsyg.2017.00928.

Rose, Nikolas. 2006. Disorders Without Borders? The Expanding Scope of Psychiatric Practice. Biosocieties 1(4): 465-484. https://doi.org/10.1017/S1745855206004078.

Rose, Nikolas. 2010. 'Screen and Intervene': Governing Risky Brains. History of the Human Sciences 23(1): 79-105

Rose, Nikolas, and Joelle M. Abi-Rached. 2013. Neuro: The New Brain Sciences and the Management of the Mind. Princeton: Princeton University Press.

Rose, Nikolas, and Joelle Abi-Rached. 2014. Governing Through the Brain Neuropolitics. Neuroscience and Subjectivity. Cambridge Anthropology 32(1): 3-23. https://doi.org/10.3167/ca.2014.320102.

SBU. 2013. ADHD - Diagnostik och behandling, vårdens organisation och patientens delaktighet. En systematisk litteraturöversikt [ADHD - Diagnostic and Treatment, Organization of Care and Patient participation. A Systematic Literature Review]. Stockholm: Statens beredning for medicinsk utvärdering (SBU). SBU-rapport nr 217. ISBN 91-85413-58-4.

Smith, Matthew. 2010. The Uses and Abuses of the History of Hyperactivity. In (De)Constructing ADHD Critical Guidance for Teachers and Teachers Educators. ed. Linda J. Graham, 23-39. New York, NY: Peter Lang.

Socialstyrelsen. 2015. Användningen av centralstimulantia vid adhd. Utvecklingen regionalt och $i$ riket [The Use of Stimulantia for ADHD. Development Regionally and Nationally].Stockholm: Socialstyrelsen.

Tait, Gordon. 2001. Pathologising Difference. Governing Personality. Asia-Pacific Journal of Teacher Education 29(1): 93-101.

Tait, Gordon. 2005. The ADHD Debate and the Philosophy of Truth. International Journal of Inclusive Education 9(1): 17-38.

Tait, Gordon. 2009. The Logic of ADHD: A Brief Review of Fallacious Reasoning. Studies in Philosophy and Education 28(3): 239-254.

Taylor, Eric. 2011. Antecedents of ADHD: A Historical Account of Diagnostic Concepts. ADHD Attention Deficit Hyperactivity Disorder 3: 69-75. https://doi.org/10.1007/s12402-010-0051-x.

te Meerman, Sanne, Laura Batstra, Hans Grietens, and Allen Frances. 2017. ADHD: A Critical Update for Educational professIonals. International Journal of Qualitative Studies on Health and Well-being. https://doi.org/10.1080/17482631.2017.1298267.

Thodelius, Charlotta, and Jörgen Lundälv. 2017. Från omognad till risk - kontroversen om ADHD i två medicinska tidskrifter [From Immaturity to Risk-The Controversy About ADHD in Two Medical Journals]. Socialmedicinsk tidskrift 94(1): 81-89.

Thomas, Philip, Patrick Bracken, Paul Cutler, Robert Hayward, Rufus May, and Salma Yasmeen. 2005. Challenging the Globalisation of Biomedical Psychiatry. Journal of Public Mental Health 4(3): 23-32.

Timimi, Sami. 2005. Naughty Boys. Anti-social Behavior, ADHD and the Role of Culture. New York, NY: Palgrave Macmillan.

Timimi, Sami. 2014. No More Psychiatric Labels: Why Formal Psychiatric Diagnostic Systems Should be Abolished. International Journal of Clinical and Health Psychology 14: 208-215.

Timimi, Sami. 2017. Non-diagnostic Based Approaches to Helping Children Who Could be Labelled ADHD and Their Families. International Journal of Qualitative Studies on Health and Well-being 12(sup1): 1298270. https://doi.org/10.1080/17482631.2017.1298270.

United Nations (UN). 2014. International Narcotics Control Board. Vienna: Report 2014. http://www.unis. unvienna.org/unis/protected/2015/AR_2014_E.pdf. Accessed 30 May 2015.

Von Wright, M. 2006. The Punctual Fallacy of Participation. Educational Philosophy and Theory 38(2): 159-170. https://doi.org/10.1111/j.1469-5812.2006.00185.x.

Whitaker, Robert. 2010. Anatomy of an Epidemic. Magic Bullets, Psychiatric Drugs, and the Astonishing Rise of Mental Illness in America. New York: Crown Publishing Group.

Zembylas, Michalinos. 2017. The Contribution of the Ontological Turn in Education: Some Methodological and Political Implications. Educational Philosophy and Theory. https://doi.org/10.1080/00131 857.2017.1309636. 